\title{
Fetal Myopericytoma: An Angel in Disguise
}

Gowda $\mathbf{M}^{1}$, Phadke $\mathbf{S}^{1}$, Verma $\mathbf{P}^{2}$ and Jaiswal $\mathbf{S}^{3}$

${ }^{1}$ Obstetrics and Gynecology, JIPMER, Pondicherry, India

${ }^{2}$ Medical Genetics, JIPMER, Pondicherry, India

${ }^{3}$ Pathology, JIPMER, Pondicherry, India

"Corresponding author: Mamatha Gowda, JIPMER, Obstetrics and Gynecology, MSR-18 JIPMER campus, Pondicherry 605006, India, Tel: 080-26720663, +917639771610; E-mail: drmamathagowda@gmail.com

Rec date: Apr 16, 2014; Acc date: Apr 26, 2014; Pub date: May 02, 2014

Copyright: ( 2014 Gowda M, et al. This is an open-access article distributed under the terms of the Creative Commons Attribution License, which permits unrestricted use, distribution, and reproduction in any medium, provided the original author and source are credited.

\begin{abstract}
This is a case of fetal myopericytoma investigated by prenatal ultrasound and confirmed by autopsy and histopathological examination after termination of pregnancy. On antenatal ultrasonography, the fetus of 20 weeks gestation had a single large multicystic neck mass with enhanced Doppler flow. Parents chose to terminate the pregnancy. On autopsy the neck mass was found to be a tumor with numerous vessels with no other associated malformations. Histopathological examination with immunohistochemistry revealed the tumor to bear the characteristics of benign myopericytoma. This is probably the earliest gestation at which fetal myopericytoma has been reported.
\end{abstract}

Keywords: Myopericytoma; Perimyocytoma; Infantile hemangioma; Myofibromatosis; Pericytic lesions

\section{Introduction}

Myopericytomas are benign pericytic tumours usually occurring in adults and involving the distal extremities. There are only two cases of antenatally detected myopericytomas described at 32-33 weeks of gestation. We are reporting a case of fetal myopericytoma involving the neck detected at an early gestation of 20 weeks.

\section{Case History}

A twenty five year old primigravida presented for evaluation of a fetal neck mass detected on ultrasound at 20 weeks of gestation. There was a large multicystic mass of size $8 \mathrm{~cm} \mathrm{X} 6 \mathrm{~cm}$ on the right side of fetal neck. There were multiple hypo-echoic spaces within the mass which on color Doppler showed increased vascular signals and large feeding vessels arising from the aorta (Figure 1A and 1B). Intracranial anatomy was normal and there were no other obvious malformations. Amniocentesis revealed a normal male karyotype. Differential diagnosis of arterio-venous malformations, haemangioma, vascular goiter and teratoma were considered. The extreme vascularity of the mass raised the possibility of cardiac failure in the fetus. The family opted to terminate the pregnancy in view of the uncertain diagnosis and prognosis.

An autopsy was done on the fetus and the same neck mass of size 8 $\mathrm{cm} \times 6.5 \mathrm{~cm}$ was found to extend from the ear lobule to the clavicle on the right side (Figure 2). The tumor was 1 dissection, numerous branching vessels were found within the mass which had extensions into the thorax, with a major feeding vessel arising from the aorta. The tumor could be enucleated easily as there were no intracranial extensions or involvement of underlying bone. Internal examination of all other systems was normal. Histopathological examination with the addition of immunohistochemistry revealed the tumor to be a benign myopericytoma (Figure 3).

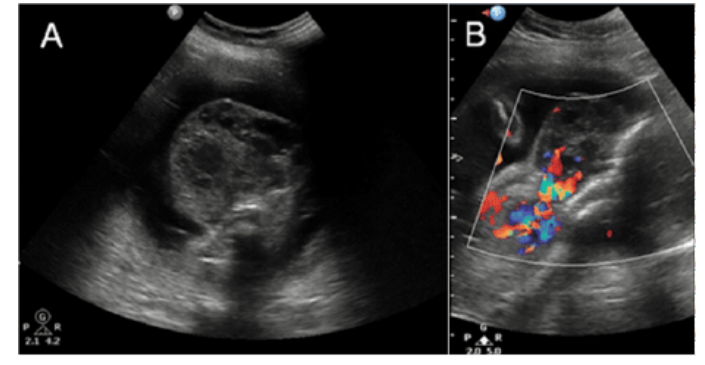

Figure 1: Ultrasound of the fetus. A): Ultrasound of the fetus showing the neck mass which on color Doppler revealed. B): Ultrasound of the fetus showing extreme vascularity

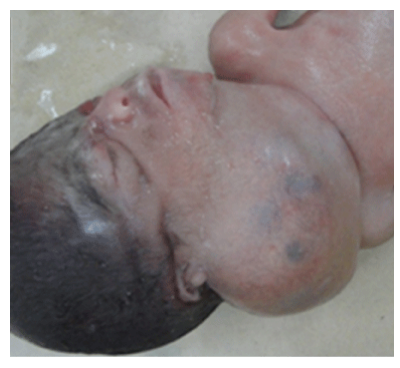

Figure 2: Autopsy of the fetus showing the neck mass which on dissection had blood filled spaces and large feeding vessels from aorta 
Page 2 of 3

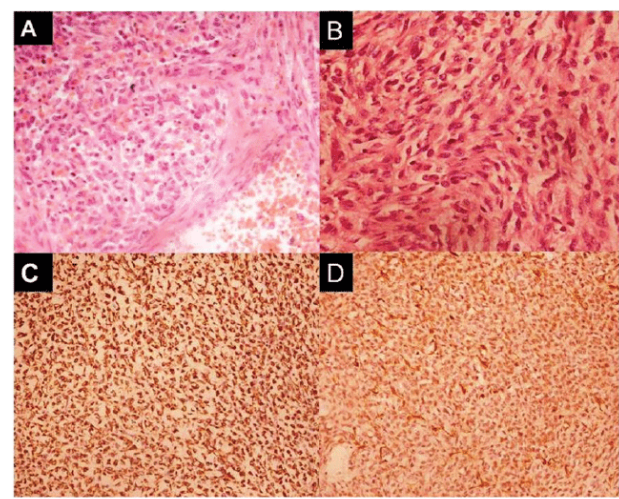

Figure 3: On Hematoxycilin and Eosin tumor cells were $(\mathrm{A})$ in sheets with intratumoral blood vessels and (B) displayed nuclear pleomorphism, coarse chromatin, conspicuous nucleoli and eosinophilic cytoplasm with spindling. On immunohistochemistry, cells positive for (C) vimentin and (D) smooth muscle actin

\section{Discussion}

This is a case of myopericytoma in a 20 weeks fetus diagnosed by prenatal ultrasound followed by autopsy and histopathological examination. This is the third case of fetal myopericytoma detected on antenatal ultrasound.

Stout and Murray [1] were the first to describe hemangio pericytoma as a tumor composed of Zimmerman's pericytes showing the characteristic 'staghorn' branching vascular spaces. However, the histological features and the branching vascular pattern which were once considered to be its characteristic feature are nonspecific, being seen in many tumors such as benign fibrous histiocytoma, synovial sarcoma, leiomyosarcoma and others [2].

The term myopericytoma was used in 1998 to describe a spectrum of tumours with clinico-pathological features that overlap with hemangio pericytoma [3]. WHO describes myopericytomas as pericytic lesions showing differentiation towards myoid/contractile perivascular cells with a characteristic tendency to grow in circumferential perivascular fashion [4]. Currently this class of tumours encompasses infantile myofibromatosis-like lesions occurring in glomangiopericytomas of adults, infantile myofibromatosis and infantile haemangiopericytoma $[5,6]$.

Myopericytoma usually presents in adults as painless, solitary, slowly growing, subcutaneous nodules involving the distal extremities and rarely the neck and proximal extremities. Only $5-10 \%$ of hemangiopericytomas affect children and the infantile variety is very rare, usually occurring within the first year of life $[7,8]$. Ultrasonographic findings are nonspecific and biopsy with immunohistochemical and ultra-structural studies are necessary to arrive at the diagnosis. Macroscopically, the tumors are uncapsulated, well circumscribed nodules of less than $2 \mathrm{~cm}$ size and are composed of oval-spindle shaped cells showing the characteristic multilayered concentric growth around the numerous vessels involved [4]. Despite overlapping of morphological pattern with myofibroma and leimyoma, myopericytomas can be distinguished by the fact that cells stain positively for alpha-smooth muscle actin $[9,10]$.
Out of the published cases of myopericytomas, only two have been reported in the fetus on antenatal ultrasound. The first case, as described by Hornoy et al. [11] had an associated cerebral anomaly recognized prenatally by ultrasonography and magnetic resonance imaging at 33 weeks of gestation. The second case report of a fetal forehead hemangio pericytoma was described by Chung et al on ultrasonography at 32 weeks of gestation. This case was followed up postnatally for 18 months after complete excision at 7 days of birth. Baby had normal growth and development without any recurrence during the period of observation [12]. Malignant myopericytoma is very rare and shows high mitotic rate, high cellularity, pleomorphism and necrosis on histopathology [5]. In this case the tumor may have an aggressive clinical behavior with recurrence or metastasis, and complete local excision with continued observation is recommended as treatment $[6,10]$.

To conclude, myopericytoma should be considered in the differential diagnosis of any vascular tumor detected antenatally in the fetus. It is important to rule out associated malformations and utilize color Doppler to look for extension of tumor into the brain [13]. If a decision is made to continue the pregnancy, then fetal echocardiography by using the Tei index and the cardiovascular scoring represents an important tool for diagnosis and monitoring of heart failure [14]. The cardiac function of the neonate after birth can be evaluated by combining tissue Doppler imaging to the echocardiography [15].

\section{References}

1. Stout AP, Murray MR (1942) HEMANGIOPERICYTOMA: A VASCULAR TUMOR FEATURING ZIMMERMANN'S PERICYTES. Ann Surg 116: 26-33.

2. Kempson RL, Fletcher CDM, Evans HL, Henrickson MR, Sibley RS (2001) Perivascular tumours. In: Atlas of tumour pathology. Tumours of the soft tissues. Fascicle 30, 3rd Series. Washington: AFIP.

3. Granter SR, Badizadegan K, Fletcher CD (1998) Myofibromatosis in adults, glomangiopericytoma, and myopericytoma: a spectrum of tumors showing perivascular myoid differentiation. Am J Surg Pathol 22: 513-525.

4. Fletcher CDM, Unni KK, Mertens F (2002) Pericytic (perivascular) tumours. In: World Health Organisation classification of tumours. Pathology and genetics. Tumours of soft tissue and bone. Lyon: IARC Press.

5. McMenamin ME, Fletcher CD (2002) Malignant myopericytoma: expanding the spectrum of tumours with myopericytic differentiation. Histopathology 41: 450-460.

6. Mentzel T, Calonje E, Nascimento AG, Fletcher CDM (1994) Infantile hemangiopericytoma versus infantile myofibromatosis. Study of a series suggesting a continuous spectrum of infantile myofibroblastic lesions. Am J Surg Pathol 18: 922-930.

7. Atkinson JB, Mahour GH, Isaacs H Jr, Ortega JA (1984) Hemangiopericytoma in infants and children. A report of six patients. Am J Surg 148: 372-374.

8. Ferrari A, Casanova M, Bisogno G, Mattke A, Meazza C, et al. (2001) Hemangiopericytoma in pediatric ages: a report from the Italian and German Soft Tissue Sarcoma Cooperative Group. Cancer 92: 2692-2698.

9. Mentzel T, Dei Tos AP, Sapi Z, Kutzner H (2006) Myopericytoma of skin and soft tissues: clinicopathologic and immunohistochemical study of 54 cases. Am J Surg Pathol 30: 104-113.

10. Dray MS, McCarthy SW, Palmer AA, Bonar SF, Stalley PD, et al. (2006) Myopericytoma: a unifying term for a spectrum of tumours that show overlapping features with myofibroma. A review of 14 cases. J Clin Pathol 59: 67-73. 
Citation: Gowda M, Phadke S, Verma P, Jaiswal S (2014) Fetal Myopericytoma: An Angel in Disguise . J Cytol Histol 5: 246. doi: 10.4172/2157-7099.1000246

Page 3 of 3

11. Hornoy P, Sonigo P, Fallet-Bianco C, Largiliere P, Teillac D, et al. (2005) Fetal hemangiopericytoma with an associated cerebral anomaly. Ultrasound Obstet Gynecol 26: 81-85.

12. Chung HYB, Chu L, Forrest C, Silver R, Toi A, et al. (2010) Fetal forehead hemangiopericytoma: prenatal diagnosis and postnatal outcome. Ultrasound Obstet Gynecol 36: 121-124.

13. Ritsuko K Pooh, Asim Kurjak (2010) Fetal brain vascularity visualized by conventional 2D and 3D power Doppler technology. Donald school journal of ultrasound in Obstetrics and Gynecology 4: 249-258.
14. Falkensammer CB, Paul J, Huhta JC (2001) Fetal congestive heart failure: correlation of Tei-index and Cardiovascular-score. J Perinat Med 29: 390-398.

15. Ciccone MM, Scicchitano P, Zito A, Gesualdo M, Sassara M, et al. (2011) Different functional cardiac characteristics observed in term/preterm neonates by echocardiography and tissue doppler imaging. Early Hum Dev 87: 555-558. 